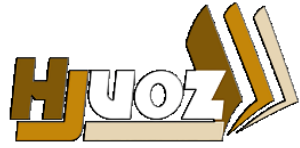

hjuoz.uoz.edu.krd p-ISSN: 2664-4673 e-ISSN: $2664-4681$

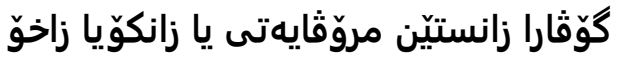

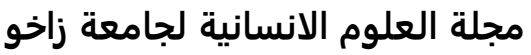

Humanities Journal of University of Zakho (HJUOZ)

Vol. 8, No. 4, pp. 705-708, December-2020.

\title{
Zaho Üniversitesi Türk Dili Bölümünde Okuyan Öğrencilerin Konuşma ve Gramerdeki Hata Bulguları
}

\author{
FIRAS TAHSIN SABIR ${ }^{1 *}$, JUMAA QADIR MOHAMMED ${ }^{1}$ \\ ${ }^{1}$ Türk Dili ve Edebiyatı Bölümü, İnsani Bilimler Fakültesi, Koya Üniversitesi, Kürdistan Bölgesi - Irak \\ ${ }^{2}$ Türk Dili Bölümü, İnsani Bilimler Fakültesi, Zaho Üniversitesi, Kürdistan Bölgesi - Irak
}

Received: 09. 2020 / Accepted: 11. 2020 / Published: 12. 2020 https://doi.org/10.26436/hjuoz.2020.8.4.656

Özet:

Zaho Üniversitesi İnsani Bilimler Fakültesi Türk Dili Bölümünde okuyan öğrencilerinin dil bilgisi sınav kağıtlarında bulunan hatalar üzerine değerlendirme yaptığımız bu çalışmanın esasını oluşturmak amacıyla ikinci, üçüncü ve dördüncü sınıfların dil bilgisi sınav kağıtlarında yapılmış hatalardan yola çıkarak yazılmıştır. Elimizde bulunan veriler incelenerek yapılan hataların nerede ve hangi başlıklarda olduğunu ortaya çıkarılmıştır. Bu hataların ana sebebi anadilin gramerini amaç dilin gramerine katmak ve anadilden amaç dile yakıştırma ve yürütüm sonucu ortaya çıkabilmesidir. Ayrıca, öğrenciler dil bilgisinde en çok ilerleyici hataya düştükleri noktalama, yazım, sözcük, söz dizimi ve eklerin kullanışı konusunda yaptıkları yanlışlıklar saptanmıştır.

Anahtar kelimeler: Anadil, Türkçe, Dil Bilgisi, Hata Analizi, Yabancı Dil.

\section{Giriș}

Dil sistemli ve aynı anda kompleks strüktüre sahip bir yöntemdir. $\mathrm{Bu}$ strüktür içerisinde her dil kendine mahsus yasaları ile önümüze çıkmaktadır. Türkçe de kendi sistemi ile dünya dilleri arasında önemli bir konuma sahiplik etmektedir. Türk dilinin ilk dönemlerden bugüne dek olan zamanı incelendiğinde temelli tarihi dikkat çekmektedir. Bu zaman zarfında Türkçe diğer ulusların da öğrenmek ve bilmek istedikleri bir dil pozizsyonu haline gelmiştir. Türkçe günümüze kadar yabancıların ilgiyle öğrenmek istedikleri bir dildir.

Bir yabancı dili başkarına öğretmek isteği eskilerden günümüze dek devam etmektedir. Akadların $M \ddot{O} 2225$ 'te kendilerinden daha ileri bir uygarlık olan Sümerlerin ülkesini ele geçirdikten sonra onların dilini öğrendiklerini ve bunun insanlık tarihinin ilk yazılı ve sözlü dil öğretimi olduğunu belirtir (Er vd., 2012: 52).

Yabancı Bir dili öğrenmek, bu dilde yazı yazmak ve hayallerini dile getirmek kuşkusuz büyük bir yetenek gerektirir. Bu yeteneği kazanabilmek de cesaret ve deneyimler sonrasında gerçekleşir.

Yalnız bu yeteneğe kavuşana kadar yapılan yanlışların görülmesi gayet normaldir. Her kim olursa olsun başka bir dili öğrenmek sırasında bu dili anadilne benzeterek ve karşılaştırarak öğrenir. Daha sonra bu beceri yazı yazma vetiresine ulaşır. Bu aşamada yapılan hatalar da ortaya çıkar, bu da gayet normaldir, çünkü bir insan kendi dilinde bile yazı yazdığında hata yapması görülebilir.

Hangi dil olursa olsun yapılan hatalar, öğrencinin anlatılanları ne kadar öğrendiğini göstermesinin yanı sıra, öğreticiye de hangi konulara ağırlık vermesi gerektiğini göstermektedir. Öğrenci dilde kullanılan kuralları doğru bir şekilde öğrenirse, bunu dilbilgisel açıdan da anlamlı bir formata oturtabilir.

Peki, nedir bu hataların nedenleri?

Öğrencilerin yazılı anlatım sırasında yaptıkları hataları farklı nedenlere bağlamak mümkündür. Anadil grameri, sözcük ve cümle yapıları hatta dilin türü ve mensubu bulunduğu dil ailesinin karakteristik özellikleri bile hedef dile hata olarak yansımaktadır. Öğrenci anadilinde düşüneceği için, hedef dili anadilinin işletim sistemine uygulayacaktır (Subaşı, 2010: 9).

\subsection{Araştırmanın Amacı}

Bu çalısmada, Üniversitede Türk Dili ve Edebiyatı okuyan öğrencilerin birinci sinıftan beri Türkçe öğreniminde karşılaştıkları sorunları nerede hata yaptıklarını takip ederek ulaşılan sorunlar:

1. Öğrencilerin sınav kağıtlarındeki bulgularda daha çok gramerde hata yaptıkları ve telaffuzda sorun, özellikle bazı harfleri telaffuz edememeleri elde edilmiştir.

2. İstikrarsızlık ve ekonomik sorunlarından kaynaklanan gelecekteki hayallerinin yıkılması ve yerine getirilmemesi.

\section{Yöntem}

$\mathrm{Bu}$ başlıkta araştırmanın modeli, verilerin toplanması ve verilerin analizi ile ilgili bilgiler verilmiştir.

\subsection{Araştırma Modeli}

Zaho Üniversitesinde öğrenim gören öğrencilerin Türkçe öğrenirken karşılaştıkları sorunları tespit etmek amacıyla betimsel modelde yapılan bu çalışmada nitel araştırma deseni kullanılmıştır. "Nitel araştırma, gözlem, görüşme ve döküman analizi gibi nitel veri toplama yöntemlerinin kullanıldığı, olguların ve olayların doğal ortamda gerçekçi ve bütüncül bir biçimde ortaya konmasına yönelik nitel bir sürecin izlendigi arastırma olarak tanımlanabilir" (Yıldırım ve Simsek, 2008: 39). Nitel araştırmalar, araştırma yapılan ya da yapılması planlanan kişilerin sahip oldukları deneyimlerinden doğan anlamların sistematik olarak incelenebilmesinde tercih edilen bir yaklaşımdır (Ekiz, 2003) (Biçer vd., 2013: 128 ).

\subsection{Verilerin Toplanması}

Bu araştırma verileri, Kuzey Irak'taki Zaho Üniversitesi Türk dili bölümü öğrencilerinin dil bilgisi sınav kağıtlarındaki gramer hataları ve konuşma sınavı yapıldıktan sonra elde edilen hataları bulgular başlığı altında karıșık olarak hem gramer hem konuşmada elde edilen hatalar bir arada verilmiştir.

\section{Bulgular}

3.1. Öğrencilerin gramer ve konuşmada yaptıkları hatalara ilişkin bulgular:

${ }^{*}$ Corresponding Author. 


\subsection{1. Ünlülerin Yanlış Söyleyişi:}

Ağız boşluğunda ve ses yolunda hiçbir engele çarpmadan çıkan seslere ünlüler denir (Hengirmen, 1999: 21).Türkçede sekiz ünlü bulunmaktadır, bu ünlülerin her biri bir söyleyiş tarzı olduğu için yabancıların bu sesleri çıkarmakta zorlandıkları görülmektedir. $\mathrm{Bu}$ sesleri telaffuz sirasında hangi harfin telaffuz edildiği çıkarılamazken hem konuşma sırasında hem yazı yazarken hata yapmaya yol açmış olacaktır. Özellikle çalışmada en çok ( $\mathrm{a}, \mathrm{e}, 1, \mathrm{i}, \mathrm{o}, \ddot{\mathrm{o}}, \mathrm{u}$, ü $)$ ünlülerde hata yapıldığ görülmektedir. Bununla birlikte bu harfleri birbiriyle karıştırıp kalın-ince veya düz-yuvarlaklık kuralını önemsemeden birbirinin yerine yazıldığ 1 ve söylendiği tespit edilmiştir. $\mathrm{O}$ ünlüsü yerine $\mathrm{u}$, $\mathrm{u}$ yerine 1,1 yerine $\mathrm{i}$, i yerine $\mathrm{e}, \mathrm{a}$ yerine e söylenmesi ve ters olarak da görülmektedirler.

Örnekler: geliyorum $>$ geleyurum, gö $z>$ güz $z$ ağrıyor $>$ ağriyor, güçlü> göçlü, lokma $>$ lukkma, size seviyorum $>$ sizị seviyorum, seni $>$ s $\underline{\text { ana }}$, hocam $>$ h hucam, ........

\subsection{2. Ünlülerin Yanlış Yazılışı:}

-Kural: Türkçede bir kelimenin ünlüsü kalın ünlü ile başladığında devam eden diğer ünlüler kalın, ince ile başladığında devam eden diğer ünlüler ince olmalıdır. Her ne kadar yuvarlak uyumu Türkçede tam olmasa da düzlükyuvarlaklık uyumuna da dikkat edlmelidir.

3.1.3. Iyelik Eklerinde: kitabım $>$ kitabim, yazını- $>$ yaziniz, arkadaşları $>$ arkadaşlari, değilim $>$ değil_m, özlemişiz $>$ özlemişız, okumazsını $>$ okumazsinn, gözü̈m $>$ gözüm.......

3.1.4. Cokluk Ekinde: sinıflar $>$ sinıfler, geliyorlar $>$ geliyorler, gittiler> gitirlar.

3.1.5. Soru Ekinde: okuyorlar mı $>$ okuyorlar mí?, söyleyecek miyim> söylecek mıyıım?, geliyor muyuzu? > geliyor mịyiz?

3.1.6. Hal Eklerinde: sinifta $>$ sinifte, seni $>$ sene, okulün>okulın, uçaktan $>$ uçakten, sinifa $>$ sinife, sinifa gidiyor $>$ sinıf므 gidiyor....

3.1.7. İsim Tamlamasında: masanı̣ üstü> masanin üstí, kol saati $>$ kol saatı.....

3.1.8. Simdiki Zamanda: geliyorum $>$ geleyurum, ağrı̣or $>$ ağriyor, arıyor $>$ arịyor, ağlıyorum $>$ ağlayurum, okuyor $>$

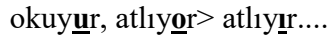

3.1.9. Genis Zamanda: olumlu: okurum- olumsuz: okumazsin $>$ okurmazsin, gelirim> gelerim.

3.1.10. Gelecek Zamanda: söyleyeceğim $>$ söyleyạcağı̆m,

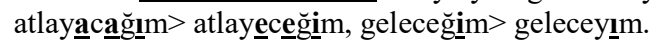

3.1.11. Görülen Geçmiș Zamanda: kaldı̣ $>$ kaldị, gördü $>$ gördu.

3.1.12. Öğrenilen Geçmiş Zaman: öğrenmịş> öğrenmış,

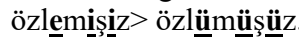

3.1.13. Gereklilik Kipinde: anlamalıyız> anlamaliyiz.

3.1.14. Şart Kipinde: kaybetse $>$ kaybets $\underline{\mathbf{a}}$, okusa $\underline{\mathbf{a}}>$ okuse.

3.1.15. Emir Kipinde: atınız $>$ atininiz, alınız $>$ aliniz

3.1.16. Yeterlilikte: okuyamazsın $>$ oku_mazsın, gelebilirim> gelebilmem.

3.1.17. İsim Hal Eklerinde: Zahoda $>$ Zahode, okuldan $>$

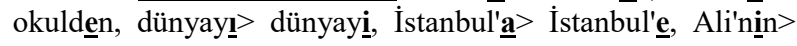
Ali'nı̄n, arkadaşıml $\underline{\mathbf{a}}>$ arkadaşımle.....
3.1.18. Diğer Kelimelerdeki Yanlıșlılar: dönüşlülük $>$ dünnüşlülük, özlemișiz $>$ özülmüsşüz, kötü> kütü, kapı > kapa, gidiyorlarım? > gidiyorlar mı? , iyi mivim? $\underline{\text { mi}}$ ?, söylemişiz $>$ söyleöiş $\underline{i z}$, geliyorsun $>$ geliyorun!, söyleyecek $>$ söyle_cek, gitti $>$ giti, okurmazsın $>$ okumaz ve okurum, gidiyoruz $>$ gitiyoruz, miyim? $>$ mi ğim?, okumazsın $>$ okumayzn, öğrencivim $>$ öğrencim/ öğrenciğim, Ayș $>$ Ayișa, iyiyim $>$ iyi_m, gịrdi $>$ gerdi, soba $>$ supa, gittim $>$ gitim, kalbimi kırdın $>$ kalbim kırıldın, asker $>$ askị, aclıktan $>$ acıktan, boyaland $>$ boyanladi, eteğ $i>$ etekii, aç gözlü $>$ aç güzlü, deyịm $>$ dayı́m, aya ayağım a ăglıyor, sandalye $>$ sandalıye.

\section{2. İstikrarsızlık ve ekonomi sorunlarından} kaynaklanan gelecekteki hayallerinin yıkılması ve yerine getirilmemesi:

Türkçe bölümünde okuyan öğrencilerin devlette bulunan sorunları dile getirerek istikrarsızlık, atanmama, geçim sıkıntısı, barınma, ulaşım gibi konularda sorunların olduğu görülmüştür. Bu sorunlar içerisinde en fazla geçim sıkıntısı ve atanmamakla ilgili olduğu, bitirip ne iş yapacağı konusunda öğrencilere büyük bir streste olmasını geleceklerini elde edememelerinin hayalini doğurtmuştur. Öğrenci dört yıl uğraşıp tüm zorluklara rağmen okulunu bitirdikten sonra ya evde oturacağım ya da serbet çalışacağım düşüncesini yaratması hem eğitim yılı içerisinde öğrenme düzeyini etkilediği hem psikolojik olarak çevreye bu korkunun yayılmasına sebep olmuştur.

\section{4. Öğretim Devamılığındaki Öneriler}

1. Dil bilgisi konuları iyi bir şekilde öğretilmeli ve diğer derslerle birlikte takip etmelidir.

2. Yazılı anlatım, dinleme ve konuşma derslerinde hataların saptanması ve geri bildirim yapılmalıdır.

3. Yazım ve seslendirme etkinliklerine önem vermek ve kelime hazinesini arttırmak. Bu şekilde konuşma becerisine de yol açacaktır.

4. Ders konularının kaynaklarını arttırmak, öğrencilerin alınan konuyla ilgili araştırmalarının istenmesi ve öğrencilerin birbirleriyle anadille konuşmak yerine Türkçe konuşmalarına teşvik etmek çünkü bu şekilde nerede hata yapıldığını öğrenir ve harflerin telaffuzunu da öğrenecektir.

\section{Tartışma ve Sonuç}

Dil bilgisi öğrenme kabiliyeti anadilinde dahi olsa kişinin iyi bir deneyim ve eğitim sahibi olmasına gerek duyulur. Çalışmada hata olarak gösterdiğimiz tüm konular düz şekilde yerine getirilirse, yanlışlıklar en aza indirilmesine çalış1ırsa da, hataya düşmemek kesinlikle öğrenen kişinin kabiliyetine dayanılır. Fakat yabancı bir dil öğrenenler için kıymetlendirme yaparken bu beceriyi daha arka planda değerlendirmek mumkün. Yukarıda anlatılan çözüm yolları aslında sadece okuyan Kürt öğrencileri değil, umumi olarak başka dil öğrenen her insanı ilgilendirmektedir. Fakat bu hususlar Kürt öğrencilerin düştükleri hatalardan elde edilmiştir. Dilcilere faydalı olmak ve tekrar bu hataların tekrarlanmaması öne sürülmüştür.

Zaho üniversitesinde yapılan bu hataları göstermek amacıyla birinci, ikinci, ücüncü, dördüncü sınıf öğrencileri ve tüm hocaları katılarak bir seminerde sunulmuştur. Bunun sebebi de bu hataları düzeltmeleri, birinci sınıftan başlayan öğrencilerin daha dikkatli olmaları, nerelerde hataya düşmelerinin bilincinde olmaları gerektiğini hatırlatmak.

Araştırmadan tepit edilen hatalar; Türkçe öğrenmeye çalışan öğrencilerin gramer sınav kağıtlarında eklerin kullanışına bakıldığında en fazla hatayı, çekim eklerinde yaptıkları tespit edilmiştir. Özellikle zaman ve hâl eklerinde hâllerin kelimeye kattığı anlamı, nerede ve ne zaman kullanılacağını fark etmeyerek hata yapmalarına neden olmuştur. Basit zaman çekimleri, ek fiil ve birleşik zamanları birbirleriyle karıştırmak. 
Yapım eklerinin kelimeye kattığı yeni anlamlarını anlamamak. Problemin yapım eklerinin çok anlamlı olmasından ve dört çeşidinde de bazılarının tekrarlanması hataya düşmelerine sebep olmuştur.

\section{Kaynakça}

Biçer, N., Çoban, İ., Bakır, S. (2014). Türkçe Öğrenen Yabancı Öğrencilerin Karşılaştı̆̆ Sorunlar: Atatürk Üniversitesi Örneği. Uluslararası Sosyal Araştırmalar Dergisi, Cilt: 7 Sayı: 29. (125-135).

Çerçi, A., Derman, S., Bardakçı, M. (2016). Yabancı Dil Olarak Türkçe Öğrenen Öğrencilerin Yazılı Anlatımlarına Yönelik Yanllş. Gaziantep Üniversitesi Sosyal Bilimler Dergisi, 15(2). (695-715).

Ekiz, Durmuş (2003). Eğitim Araştırma Yöntem ve Metodlarına Giriş, Ankara: Anı Yayıncılık.

Er, O., Biçer, N., Bozkırlı, K., Ç. (2012). Yabancılara Türkçe Öğretiminde Karşılaşılan Sorunların Ilgili Alan Yazını Işı̆̆ında Değerlendirilmesi. Uluslararası Türkçe Edebiyat Kültür Eğitim Dergisi, Sayı: 1/2. (51-69). Türkiye.
Hengirmen, M. (1997). Yabancı Dil Öğretim Yöntemleri ve TÖMER Yöntemi. Ankara: Engin Yayınevi.

Hengirmen, M. (1999). Yabancılar için Türkçe Dilbilgisi. Ankara: Engin Yayınevi.

Lado, R. (1957). Linguistics Across Cultures: Applied Linguistics for Language Teachers, Michigan: The University of Michigan Press.

Subaşı Adalar, D. (2010). Tömer'de Yabancı Dil Olarak Türkçe Ögrenen Arap Öğrencilerin Kompozisyonlarında Hata Analizi. Dil Dergisi, Sayı: 148. (6-16).

Şahin, Y. (2007). Yabancı Dil Öğretiminin Eğitbilimsel Ve Dilbilimsel Temelleri. Erciyes Üniversitesi Sosyal Bilimler Enstitüsü Dergisi, Say1: 22. (465-470).

Yağmur, Şahin, E. (2013). Yabancı Dil Olarak Türkçe Öğrenen Ögrencilerin Yazılı Anlatımlarındaki Ek Yanlışları. Tarih Okulu Dergisi (TOD), 6, Say1: 15. (433-449).

Yıldırım, Ali ve Şimşek, Hasan (2008). Sosyal Bilimlerde Nitel Araştırma Yöntemleri, Ankara: Seçkin Yayınevi. 


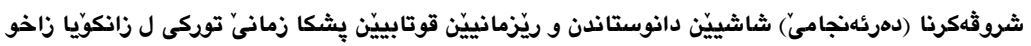

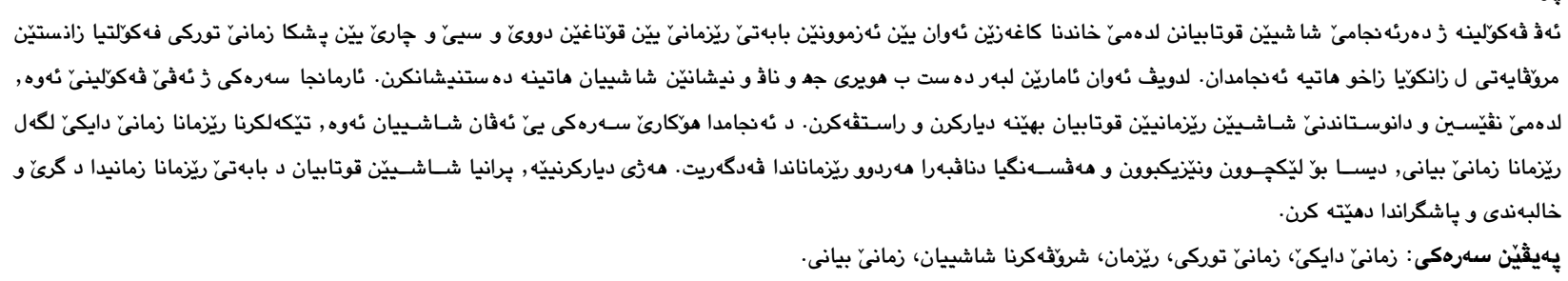

\section{Analyzing the results of speaking and grammar errors for students of the Turkish Language Department at Zakho}

\section{Abstract:} University

The main purpose of this study was to examine the mistakes of grammer test papers of students studying in the Turkish language department of Faculty of Humanities at Zaho University. The study evaluates the mistakes of second, third and fourth grade students. After examining the collected data, we have discovered where and in which titles the mistakes were made. The main reasons of those mistakes was mixing the grammar of the mother language to the grammar of the target language as well as applying and fitting the mother language grammer to the target language.

In addition, students have made more mistakes in their use of spelling, punctuation, vocabulary, syntax and suffixes compared to the grammar.

Keywords: Mother Tongue, Turkish, Grammar, Error Analysis, Foreign Language. 